\title{
Early Postoperative Results and Complications of using the EX-PRESS Shunt in uncontrolled Uveitic Glaucoma: A Case Series of Preliminary Results
}

\author{
1 Jacky WY Lee, ${ }^{2}$ Jonathan CH Chan, ${ }^{3}$ Li Qing, ${ }^{4}$ Jimmy SM Lai
}

\begin{abstract}
Purpose: The purpose of this case series is to describe the efficacy of the EX-PRESS shunt in uveitic glaucoma.

Methods: This prospective case series sequentially recruited uveitic glaucoma subjects with intraocular pressure $(\mathrm{IOP})>21$ $\mathrm{mm} \mathrm{Hg}$ despite maximal topical antiglaucoma medications from July 2012 to July 2013 in Hong Kong. All subjects received a trabeculectomy with mitomycin C (MMC) and EX-PRESS shunt implantation. The primary outcome measures included preoperative IOP and postoperative IOP on day 1, 1 week, 1 month, and every 3 months thereafter. The secondary outcome measures included postoperative complications and follow-up procedures, pre- and postoperative Snellen best corrected visual acuity and cup-disc ratio, as well as the number of antiglaucoma medication required.
\end{abstract}

Results: In a case series of five subjects with uncontrolled uveitic glaucoma, two had inactive anterior uveitis, and three had active panuveitis. The mean preoperative IOP was $35.4 \pm$ $12.6 \mathrm{~mm} \mathrm{Hg}$ on $3.8 \pm 0.5$ antiglaucoma eye drops. The mean day 1,1 week and 1 month IOP's were $6.6 \pm 3.7 \mathrm{~mm} \mathrm{Hg}, 7.2 \pm 3.2$ $\mathrm{mm} \mathrm{Hg}$, and $12.6 \pm 8.2 \mathrm{~mm} \mathrm{Hg}$, respectively. One case required subconjunctival MMC injections postoperatively; two required conjunctival resuture for leakage; and two had early postoperative hypotony that resolved after oral prednisolone. At 6 months, the mean IOP was $13.2 \pm 4.6 \mathrm{~mm} \mathrm{Hg}$. Four out of five subjects had IOP $<21 \mathrm{~mm} \mathrm{Hg}$ without medication, and all had IOP $<21 \mathrm{~mm}$ $\mathrm{Hg}$ with antiglaucoma medication.

Conclusion: The EX-PRESS shunt demonstrates good IOP control with a propensity for hypotony in the early postoperative period in this small uveitic glaucoma series.

Keywords: EX-PRESS, Uveitic glaucoma, Intraocular pressure, Success, Complications, Medication.

\footnotetext{
${ }^{1,2}$ Associate Professor, ${ }^{3}$ Clinical Assistant Professor ${ }^{4}$ Clinical Professor

${ }^{1}$ Department of Ophthalmology, Caritas Medical Centre University of Hong Kong, Hong Kong

2Department of Ophthalmology, Queen Mary Hospital, Hong Kong

${ }^{3,4}$ Department of Ophthalmology, University of Hong Kong Hong Kong

Corresponding Author: Jacky WY Lee, Associate Professor Department of Ophthalmology, Caritas Medical Centre, 111 Wing Hong St Kowloon, Hong Kong, Phone: +852-34097421 Fax: +852-23070582, e-mail: jackywylee@gmail.com
}

How to cite this article: Lee JWY, Chan JCH, Qing L, Lai JSM. Early Postoperative Results and Complications of using the EXPRESS Shunt in uncontrolled Uveitic Glaucoma: A Case Series of Preliminary Results. J Current Glau Prac 2014;8(1):20-24.

Source of support: Nil

Conflict of interest: None

\section{INTRODUCTION}

Glaucoma is a serious complication that can occur in 10 to $20 \%$ of uveitis and even a higher prevalence in cases of Fuchs heterochromic cyclitis, herpes, or sarcoidosis-related uveitis. ${ }^{1-3}$ The intraocular pressure (IOP) elevation in uveitic glaucoma can be due to a number of reasons including: increased aqueous viscosity and protein, ${ }^{4,5}$ reduced trabecular meshwork function by inflammatory cytokines, pigments, trabeculitis and eventual trabeculocyte cytotoxicity. ${ }^{6}$ In addition, the treatment of uveitis with topical corticosteroids can also induce significant IOP elevation. Around $21 \%$ of adults have been reported to have intermediate IOP rise after topical dexamethasone use. ${ }^{7}$

The treatment of IOP rise in uveitis is most commonly with topical or oral antiglaucoma medications, but the response to treatment is often variable ranging from 0 to $80 \%$ reductions. When maximal antiglaucoma medications fail to control IOP, filtration surgery is often required; although, the success rate in uveitic glaucoma is often poorer than that of primary glaucomas. The success rate of trabeculectomy in uveitic glaucoma, without the use of adjunctive antimetabolites, is only about $30 \%$ and slightly improved to $50 \%$ at 5 years with the use of 5-fluorouracil (5-FU). ${ }^{8}$

The EX-PRESS glaucoma filtration device is a metallic implant that provides an artificial channel to drain the aqueous into the subconjunctival space and it is less invasive and more precise than the traditional trabeculectomy. It provides a significantly lower IOP in the first 3 years postoperatively and less antiglaucoma medication requirements 5 years postoperatively compared to trabeculectomy. ${ }^{9}$ The EXPRESS does not require a sclerectomy or peripheral iridectomy; hence, there is less inflammation and less risk of blockage of the inner window by fibrin, blood, or iris. The rate of postoperative hypotony ( $4 \%$ vs $32 \%$ ) and choroidal effusion ( $8 \%$ vs 38\%) is also significantly less with the EXPRESS than in traditional trabeculectomy. ${ }^{10}$ 
While, the efficacy of the EX-PRESS has been established in the use of primary open angle glaucoma (POAG), its efficacy in uveitic glaucoma is less well studied. The purpose of this case series was to describe the efficacy of the EX-PRESS mini shunt device in uncontrolled uveitic glaucoma.

\section{PATIENTS AND METHODS}

This prospective case series adhered to the tenets of the Declaration of Helsinki. Informed patient consent and approval by the Institutional Review Board were obtained prior to study commencement. The authors declare no financial or proprietary interests. All subjects were recruited sequentially from the ophthalmology clinic of a tertiary university hospital, Queen Mary Hospital, in Hong Kong during July 2012 to July 2013. The inclusion criteria consisted of consenting individuals with uncontrolled uveitic glaucoma with IOP $>21 \mathrm{~mm} \mathrm{Hg}$ despite maximal topical antiglaucoma medications. The exclusion criteria included: age $<18$ years, those who were unable to consent, only eye, previous glaucoma surgery, or those with less than 6 months follow-up.

The surgical procedure for EX-PRESS shunt implantation was as follows:

1. Local anesthesia with Xylocaine gel 2\% (AstraZeneca, 1004 Middlegate Road, Ontario, Canada).

2. Fornix-based conjunctiva opening.

3. Application of mitomycin C (MMC) $0.4 \mathrm{mg} / \mathrm{ml}$ for 3 minutes followed by irrigation with balanced salt solution.

4. A $4 \times 4 \mathrm{~mm}$ partial thickness sclera flap.

5. Paracentesis and anterior chamber reformation with a cohesive viscoelastic.

6. Injection of the EX-PRESS shunt $(50 \mu \mathrm{m})$ into the 'blueline' junction adjacent to the clear cornea with the aid of a 27-gauge needle.

7. No sclerectomy and peripheral iridectomy was required.

8. The sclera flap was closed with 10-O Nylon.

9. The conjunctival wound was closed with 10-O Nylon or 8-O Vircyl in an interrupted suture manner.

The primary outcome measures were preoperative IOP and postoperative IOP on day 1, 1 week, 1 month and every 3 months thereafter. The secondary outcome measures included postoperative complications and follow-up procedures, pre- and postoperative Snellen best corrected visual acuity (BCVA), and cup-disc ratio (CDR), as well as the number of antiglaucoma medication required.

Descriptive analysis of IOP, number of complications and procedures, pre- and postoperative eye drops, and BCVA and CDR were presented. Means were expressed as mean \pm standard deviation. Complete success was defined as $\mathrm{IOP} \leq 21 \mathrm{~mm} \mathrm{Hg}$ without antiglaucoma medication and partial success was defined as IOP $\leq 21 \mathrm{~mm} \mathrm{Hg}$ with topical antiglaucoma medication.

\section{RESULTS}

There were five patients recruited during the study period. All subjects were males, ethnic Chinese with a mean age of $48.4 \pm 12.9$ years. There were three right eyes and two left eyes. All subjects had uncontrolled uveitic glaucoma with IOP $>21 \mathrm{~mm} \mathrm{Hg}$ despite maximum topical antiglaucoma eye drops and open angles on gonioscopy. The mean preoperative CDR was $0.6 \pm 0.3$.

Two subjects had anterior uveitis and had no ocular inflammation for 6 months prior to the EX-PRESS implantation. Three subjects with panuveitis had persistent inflammation leading up to the EX-PRESS implantation and were on oral steroids or oral immunosuppressants (cyclosporine and azathioprine). Two of these three patients had a posterior vitrectomy to clear up the vitritis and one required repeated intravitreal steroid injections prior the EX-PRESS implantation.

The preoperative Snellen BCVA ranged from 0.1 to counting fingers (CFs). The mean number of preoperative antiglaucoma eye drops was $3.8 \pm 0.5$ and the three subjects with active panuveitis required oral acetazolamide $250 \mathrm{mg}$ four times daily. The mean preoperative IOP was $35.4 \pm 12.6$ $\mathrm{mm} \mathrm{Hg}$ with maximal medication. The mean day 1,1 week, and 1 month IOP's were $6.6 \pm 3.7 \mathrm{~mm} \mathrm{Hg}, 7.2 \pm 3.2 \mathrm{~mm} \mathrm{Hg}$, and $12.6 \pm 8.2 \mathrm{~mm} \mathrm{Hg}$ respectively (Graph 1).

Postoperatively, one case required four subconjunctival MMC (0.02 mg in $0.1 \mathrm{ml})$ injections during the first month for early postoperative scarring as determined by prominent conjunctival vascular injection and a flattened bleb. Two cases required conjunctival resuture for conjunctival

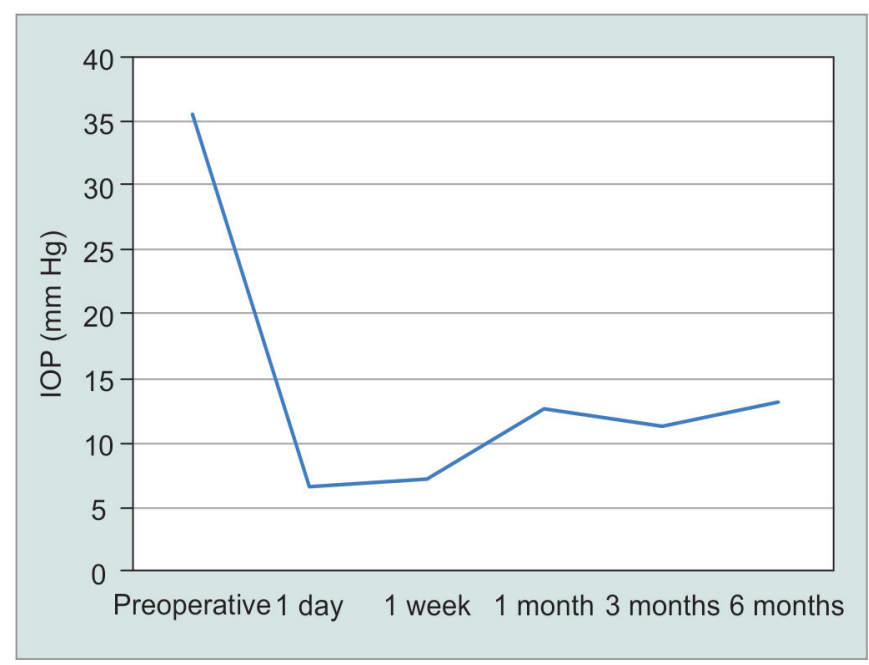

Graph 1: IOP change after EX-PRESS in uveitic glaucoma 


\begin{tabular}{|c|c|c|c|c|c|c|c|c|c|c|c|c|c|c|c|c|}
\hline \multicolumn{5}{|c|}{ Subject demographics } & \multicolumn{6}{|c|}{ Early postoperative complications } & \multicolumn{2}{|c|}{$\begin{array}{c}\text { Anti-glaucoma eye } \\
\text { drops }\end{array}$} & \multicolumn{2}{|c|}{ Cup-disk-ratio } & \multicolumn{2}{|c|}{$\begin{array}{l}\text { Snellen best } \\
\text { corrected VA }\end{array}$} \\
\hline $\begin{array}{l}\text { Case } \\
\text { no. }\end{array}$ & Sex & Age & $\begin{array}{l}\text { Opera- } \\
\text { ted eye }\end{array}$ & $\begin{array}{l}\text { Diag- } \\
\text { nosis }\end{array}$ & $\begin{array}{l}\text { Early } \\
\text { hypotony } \\
\text { (ciliary } \\
\text { body shut- } \\
\text { down) }\end{array}$ & $\begin{array}{l}\text { Choroidal } \\
\text { effusion }\end{array}$ & $\begin{array}{l}\text { Shallow } \\
\text { anterior } \\
\text { chamber }\end{array}$ & $\begin{array}{l}\text { Hypo- } \\
\text { tonous } \\
\text { maculo- } \\
\text { pathy }\end{array}$ & $\begin{array}{l}\text { Bleb leak } \\
\text { (con- } \\
\text { junctival } \\
\text { reces- } \\
\text { sion) }\end{array}$ & $\begin{array}{l}\text { Bleb } \\
\text { scar- } \\
\text { ring }\end{array}$ & $\begin{array}{l}\text { Pre- } \\
\text { operative } \\
\text { eye } \\
\text { drops } \\
\text { (no.) }\end{array}$ & $\begin{array}{l}6 \text { mth } \\
\text { eye } \\
\text { drops } \\
\text { (no.) }\end{array}$ & $\begin{array}{l}\text { Pre- } \\
\text { ope- } \\
\text { rative }\end{array}$ & 6 mths & $\begin{array}{l}\text { Pre- } \\
\text { ope- } \\
\text { rative }\end{array}$ & 6 mths \\
\hline 1 & M & 62 & Right & $\begin{array}{l}\text { Panuveitis } \\
\text { (active) }\end{array}$ & - & - & - & - & - & - & 3 & 0 & 0.6 & 0.4 & 0.1 & 0.5 \\
\hline 2 & M & 49 & Right & $\begin{array}{l}\text { Anterior } \\
\text { uveitis } \\
\text { (inactive) }\end{array}$ & - & - & 1 & - & 1 & 1 & 4 & 4 & 0.9 & 0.9 & 0.3 & 0.4 \\
\hline 3 & M & 52 & Left & $\begin{array}{l}\text { Anterior } \\
\text { uveitis } \\
\text { (inactive) }\end{array}$ & - & - & - & - & 1 & - & 4 & 0 & 0.9 & 0.9 & 0.7 & 0.8 \\
\hline 4 & M & 52 & Left & $\begin{array}{l}\text { Panuveitis } \\
\text { (active) }\end{array}$ & 1 & 1 & - & 1 & - & - & 4 & 0 & 0.4 & 0.4 & $\mathrm{CF}$ & 0.1 \\
\hline 5 & $M$ & 27 & Right & $\begin{array}{l}\text { Panuveitis } \\
\text { (active) }\end{array}$ & 1 & - & 1 & - & - & - & 4 & 0 & 0.4 & 0.4 & $\mathrm{CF}$ & 0.05 \\
\hline
\end{tabular}

recession with leakage postoperatively. Two cases had early postoperative hypotony due to ciliary body shutdown that resolved within the first month after oral prednisolone of $30 \mathrm{mg}$ daily $(0.5 \mathrm{mg} / \mathrm{kg} /$ day $)$ for 1 week with gradual tapering. Of these two cases, one developed a shallow anterior chamber with near iridocorneal touch requiring anterior chamber reformation with viscoelastics. This case was further complicated by choroidal detachment with residual hypotony maculopathy with a 6-month postoperative BCVA of 0.1 (preoperative BCVA was CF) (Table 1).

At 3 months, the mean IOP was $11.4 \pm 3.6 \mathrm{~mm} \mathrm{Hg}$. At 6 months, the mean IOP was $13.2 \pm 4.6 \mathrm{~mm} \mathrm{Hg}$ and the mean number of antiglaucoma medication was $0.8 \pm 1.8$. Four out of the five subjects had IOP $<21 \mathrm{~mm} \mathrm{Hg}$ at 6 months without antiglaucoma medication (complete success) and all had IOP $<21 \mathrm{~mm} \mathrm{Hg}$ with antiglaucoma medication (partial success). The mean BCVA and CDR at 6 months were 0.4 \pm 0.3 and $0.6 \pm 0.3$, respectively.

\section{DISCUSSION}

The management of glaucoma in uveitis poses considerable challenges. The success rate of using glaucoma drainage device in uveitic glaucoma is higher than in standard trabeculectomy. The success rate for the Molteno drainage device has been reported to be $87 \%$ at 5 years, ${ }^{11} 94 \%$ at 1 year for the Ahmed drainage device, ${ }^{12}$ and $91.7 \%$ at 2 years for the Baerveldt drainage device. ${ }^{13}$ In our small case series, the complete success of EX-PRESS shunt for uveitic glaucoma is $80 \%(4 / 5)$ at 6 months without medication, and the partial success is $100 \%(5 / 5)$ at 6 months with antiglaucoma medication. Our findings are in line with a study by Reyes et al, ${ }^{14}$ reporting a success of $86 \%$ with or without medication and $73 \%$ without medication at 10 months after EX-PRESS. However, the population in Reyes' study consisted of both primary and secondary glaucomas, including uveitic glaucoma, thus, their success is likely to be higher than for uveitic glaucoma alone.

The use of postoperative 5-FU injections was demonstrated to improve the success of trabeculectomy in uveitic glaucoma by $50 \%{ }^{8}$ However, given the predisposition to ciliary body toxicity from the absorption of antimetabolites, the risk and benefit of which must be balanced. In our case series, one subject with signs of early bleb failure, including conjunctival injection and a flattened bleb, received four postoperative injections of subconjunctival MMC within the first month. The bleb was salvaged and he achieved a complete success at 6 months. As for the choice of MMC vs 5-FU, reports have shown similar efficacy between the two in terms of IOP control. ${ }^{15-17}$ The use of postoperative antimetabolite injections was avoided in our subjects with overfiltration and ciliary body shutdown.

Postoperative hypotony is common in uveitic glaucoma because uveitis itself releases inflammatory cytokines that are toxic to the ciliary body, ${ }^{18}$ and the use of intraoperative MMC can further exacerbate ciliary body toxicity. A history of posterior vitrectomy for vitritis also predisposes the eye to hypotony due to removal of the supporting vitreous. In our series, two cases had ciliary body shutdown with hypotony but both resolved within the first month after a short course of oral steroids. For the case that had a resultant hypotony maculopathy, he had a posterior vitrectomy within 1 month prior to the EX-PRESS implantation; his BCVA after the EX-PRESS procedure improved from his preoperative 
level. Kaburaki et $\mathrm{al}^{19}$ reported that the rate of hypotony following trabeculectomy for uveitic glaucoma was $28.3 \%$; however, this rate was for long-standing ocular hypotony in a population of inactive uveitis at the time of surgery. Thus, a direct comparison cannot be made with our series that reports early hypotony.

In theory, it is best to wait until the intraocular inflammation is settled for months before glaucoma surgery for uveitic glaucoma but in reality, the IOP is commonly uncontrolled during active inflammation and like in our series, three of the subjects had active panuveitis with uncontrolled IOP despite maximal topical and systemic antiglaucoma medications. Despite implanting the EX-PRESS in the setting of active uveitis, all three subjects were able to achieve complete success at 6 months.

The EX-PRESS shunt has been advocated to offer better early postoperative IOP stability and less hypotony due to a smaller lumen size ( 50 or $200 \mu \mathrm{m}$ ) versus the largely visible sclera window of a traditional trabeculectomy. The published early postoperative hypotony rates for EX-PRESS in POAG ranges from 4.0 to $47.2 \%$ vs 14.0 to $47.4 \%$ in traditional trabeculectomy. ${ }^{20}$ The rate of postoperative hypotony in uveitic glaucoma is expected to be higher like in our series, $40 \%(2 / 5)$, due to the possibility of ciliary body shutdown from both inflammation and antimetabolite toxicity as well as after posterior vitrectomy for vitritis. Compared to the Ahmed valve that has a resistance to aqueous outflow, the rate of early postoperative hypotony is around $9 \%$ in those with uveitis from systemic disease. ${ }^{21}$ However, glaucoma drainage devices are associated with other complications like corneal decompensation, extraocular motility disorders, conjunctival thinning, and hypertensive phase that are seldom seen with the EX-PRESS. Cyclophotocoagulation is an alternative treatment modality but has a postoperative hypotony rate of $19 \%$ in uveitic glaucoma ${ }^{22}$ together with risks of increased inflammation, retinal detachment and phthisical changes.

Very few studies have reported the early postoperative results and complications of using the EX-PRESS shunt for uveitic glaucoma alone. The surgical approach to the management of uveitic glaucoma will vary depending on center and surgeon preference. Our single center, noncomparative case series has reported the early postoperative outcomes and complications of using the EX-PRESS in a small sample of uveitic glaucomas. The EX-PRESS shunt can successfully normalize IOP in the majority of uveitic glaucoma subjects, although, there is a higher propensity for hypotony in the early postoperative period compared to other glaucoma drainage devices. Larger trials are warranted to establish the long-term efficacy of using the EX-PRESS for the treatment of uveitic glaucoma, as well as to compare its efficacy with traditional trabeculectomy and glaucoma drainage devices.

\section{REFERENCES}

1. Merayo-Lloves J, Power WJ, Rodriguez A, Pedroza-Seres M, Foster CS. Secondary glaucoma in patients with uveitis. Ophthalmologica 1999;213(5):300-304.

2. La Hey E, de Vries J, Langerhorst CT, Baarsma GS, Kijlstra A. Treatment and prognosis of secondary glaucoma in Fuchs' heterochromic iridocyclitis. Am J Ophthalmol 1993 Sep;116(3): 327-340.

3. Miserocchi E, Waheed NK, Dios E, Christen W, Merayo J, Roque M, Foster CS. Visual outcome in herpes simplex virus and varicella zoster virus uveitis: a clinical evaluation and comparison. Ophthalmology 2002 Aug;109(8):1532-1537.

4. Peretz WL, Tomasi TB. Aqueous humor proteins in uveitis. Immunoelectrophoretic and gel diffusion studies on normal and pathological human aqueous humor. Arch Ophthalmol 1961 Jan;65:20-23.

5. Epstein DL, Hashimoto JM, Grant WM. Serum obstruction of aqueous outflow in enucleated eyes. Am J Ophthalmol 1978 Jul;86(1):101-105.

6. Clark AF, Lane D, Wilson K, Miggans ST, McCartney MD. Inhibition of dexamethasone-induced cytoskeletal changes in cultured human trabecular meshwork cells by tetrahydrocortisol. Invest Ophthalmol Vis Sci 1996 Apr;37(5):805-813.

7. Fan DS, Yu CB, Chiu TY, Wong CY, Ng JS, Pang CP, Lam DS. Ocular-hypertensive and anti-inflammatory response to rimexolone therapy in children. Arch Ophthalmol 2003 Dec;121(12): 1716-1721.

8. Towler HM, Bates AK, Broadway DC, Lightman S. Primary trabeculectomy with 5-fluorouracil for glaucoma secondary to uveitis. Ocul Immunol Inflamm 1995;3(3):163-170.

9. de Jong L, Lafuma A, Aguadé AS, Berdeaux G. Five-year extension of a clinical trial comparing the EX-PRESS glaucoma filtration device and trabeculectomy in primary open-angle glaucoma. Clin Ophthalmol 2011;5:527-533.

10. Maris PJ Jr, Ishida K, Netland PA. Comparison of trabeculectomy with Ex-PRESS miniature glaucoma device implanted under scleral flap. J Glaucoma 2007 Jan;16(1):14-19.

11. Molteno AC, Sayawat N, Herbison P. Otago glaucoma surgery outcome study: long-term results of uveitis with secondary glaucoma drained by Molteno implants. Ophthalmology 2001 Mar;108(3):605-613.

12. Da Mata A, Burk SE, Netland PA, Baltatzis S, Christen W, Foster CS. Management of uveitic glaucoma with Ahmed glaucoma valve implantation. Ophthalmology 1999 Nov;106(11):2168-2172.

13. Ceballos EM, Parrish RK, Schiffman JC. Outcome of Baerveldt glaucoma drainage implants for the treatment of uveitic glaucoma. Ophthalmology 2002 Dec;109(12):2256-2260.

14. Reyes M, Sarkisian SR. P200 Express shunt implantation in neovascular glaucoma, uveitic glaucoma, and primary openangle glaucoma. Invest Ophthalmol Vis Sci 2010;51:4438.

15. Ceballos EM, Beck AD, Lynn MJ. Trabeculectomy with antiproliferative agents in uveitic glaucoma. J Glaucoma 2002 Jun;11(3):189-196. 
16. Prata JA Jr, Neves RA, Minckler DS, Mermoud A, Heuer DK. Trabeculectomy with mitomycin C in glaucoma associated with uveitis. Ophthalmic Surg 1994 Sep-Oct;25(9):616-620.

17. Wright MM, McGehee RF, Pederson JE. Intraoperative mitomycin-C for glaucoma associated with ocular inflammation. Ophthalmic Surg Lasers 1997 May;28(5):370-376.

18. Sung VC, Barton K. Management of inflammatory glaucomas. Curr Opin Ophthalmol 2004 Apr;15(2):136-140.

19. Kaburaki T, Koshino T, Kawashima H, Numaga J, Tomidokoro A, Shirato S, Araie M. Initial trabeculectomy with mitomycin C in eyes with uveitic glaucoma with inactive uveitis. Eye (Lond) 2009 Jul;23(7):1509-1517.
20. Buys YM. Trabeculectomy with ExPRESS: weighing the benefits and cost. Curr Opin Ophthalmol 2013 Mar;24(2): 111-118.

21. Woreta F, Thorne JE, Jabs DA, Kedhar SR, Dunn JP. Risk factors for ocular complications and poor visual acuity at presentation among patients with uveitis associated with juvenile idiopathic arthritis. Am J Ophthalmol 2007 Apr;143(3):647-655.

22. Murphy CC, Burnett CA, Spry PG, Broadway DC, Diamond JP. A two centre study of the dose-response relation for transscleral diode laser cyclophotocoagulation in refractory glaucoma. $\mathrm{Br} \mathbf{J}$ Ophthalmol 2003 Oct;87(10):1252-1257. 